

\title{
Amino-polyvinyl Alcohol Coated Superparamagnetic Iron Oxide Nanoparticles are Suitable for Monitoring of Human Mesenchymal Stromal Cells In Vivo
}

Frank Schulze, Anke Dienelt, Sven Geissler, Paul Zaslansky, Janosch Schoon, Katja Henzler, Peter Guttmann, Azza Gramoun, Lindsey Crowe, Lionel Maurizi, et al.

\section{To cite this version:}

Frank Schulze, Anke Dienelt, Sven Geissler, Paul Zaslansky, Janosch Schoon, et al.. Amino-polyvinyl Alcohol Coated Superparamagnetic Iron Oxide Nanoparticles are Suitable for Monitoring of Human Mesenchymal Stromal Cells In Vivo. Small, 2014, pp.n/a-n/a. 10.1002/smll.201400707. hal02163382

\section{HAL Id: hal-02163382 \\ https://hal.science/hal-02163382}

Submitted on 9 Mar 2021

HAL is a multi-disciplinary open access archive for the deposit and dissemination of scientific research documents, whether they are published or not. The documents may come from teaching and research institutions in France or abroad, or from public or private research centers.
L'archive ouverte pluridisciplinaire HAL, est destinée au dépôt et à la diffusion de documents scientifiques de niveau recherche, publiés ou non, émanant des établissements d'enseignement et de recherche français ou étrangers, des laboratoires publics ou privés. 


\section{WILEY-VCH}

1 DOI: 10.1002/ ((please add manuscript number))

\section{Article type: Full Paper} 3 34

\section{Title}

Amino-polyvinyl alcohol coated superparamagnetic iron oxide nanoparticles are suitable for monitoring of human mesenchymal stromal cells in vivo

\section{Authors}

Frank Schulze, Anke Dienelt, Sven Geissler, Paul Zaslansky, Janosch Schoon, Katja Henzler, Peter Guttmann, Azza Gramoun, Lindsey A. Crowe, Lionel Maurizi, Jean-Paul Vallée,

\section{Heinrich Hofmann, Georg N. Duda*, Andrea Ode}

Frank Schulze, Dr. Anke Dienelt, Dr. Sven Geissler, Dr. Paul Zaslansky, Janosch Schoon, Prof. Georg N. Duda, Dr. Andrea Ode

Julius Wolff Institute, Charité - Universitätsmedizin Berlin, 13353 Berlin, Germany

E-mail: georg.duda@charite.de

\section{Dr. Katja Henzler, Dr. Peter Guttmann}

Institute for Soft Matter and Functional Materials, Helmholtz-Zentrum für Materialien und Energie GmbH, 14109 Berlin, Germany

Dr. Azza Gramoun, Dr. Lindsey A. Crowe, Prof. Jean-Paul Vallée

4 Department of Radiology, Geneva University Hospitals and University of Geneva, 1205

\section{Geneva, Switzerland}

\section{Dr. Lionel Maurizi, Prof. Heinrich Hofmann}

Laboratory of Powder Technology, Ecole Polytechnique Fédérale de Lausanne (EPFL), 1015

Lausanne, Switzerland

1 Keywords: mesenchymal stromal cells, superparamagnetic iron oxide nanoparticles,

polyvinylalcohol, magnetic resonance imaging, cell based therapies 


\section{WILEY-VCH} $\underline{\text { SPIONs allowed MSC-monitoring in vivo. }}$

\section{Abstract} oxide nanoparticles (SPIONs). vivo.

Mesenchymal stromal cells (MSCs) are promising candidates in regenerative cell-therapies. However, optimizing their number and route of delivery remains a critical issue, which can be addressed by monitoring the MSCs' bio-distribution in vivo using super-paramagnetic iron-

$\underline{\text { In this study, amino-polyvinyl alcohol coated (A-PVA) SPIONs were introduced for cell- }}$ labelling and visualization by magnetic resonance imaging (MRI) of human MSCs.

$\underline{\text { Size and surface charge of A-PVA-SPIONs differed depending on their solvent. Under MSC- }}$ labeling conditions, A-PVA-SPIONs had a hydrodynamic diameter of $42 \pm 2 \mathrm{~nm}$ and a negative Zeta potential of $25 \pm 5 \mathrm{mV}$, which enabled efficient internalization by MSCs without the need to use transfection agents. Transmission X-ray microscopy localized APVA-SPIONs in intracellular vesicles and as cytosolic single particles. After identifying noninterfering cell-assays and determining the delivered and cellular dose, in addition to the administered dose, A-PVA-SPIONs were found to be non-toxic to MSCs and non-destructive towards their multi-lineage differentiation potential. Surprisingly, MSC migration was increased. In MRI, A-PVA-SPION-labelled MSCs were successfully visualized in vitro and in

In conclusion, A-PVA-SPIONs had no unfavorable influences on MSCs, although it became 


\section{WILEY-VCH}

\section{Introduction}

Mesenchymal stromal cells (MSCs) have gained much interest as a promising source for cellbased therapies. Their potential to regenerate damaged tissue has been attributed to their ability of self-renewal, differentiation into a variety of specialized cell types (e.g. in bone MSCs are able to differentiate into bone-forming osteoblasts) and migration towards gradients of growth factors secreted by damaged tissue. ${ }^{[1]}$ Experimental cell-therapy approaches in animals using MSCs led to promising results for a number of neurological, myocardial and musculoskeletal disorders (e.g. femoral head necrosis, osteogenesis imperfecta, and osteoarthritis). ${ }^{[2-7]}$ Even though numerous clinical trials have been initiated and some revealed a degree of success, a broad clinical application of such therapies is still not available. $^{[8,}$ 9] Critical parameters for successfully transferring results from animal experiments to clinical application include the number of transplanted cell and their cultivation and delivery process. Visualizing and monitoring the temporal and spatial distribution of transplanted cells can provide valuable insight into understanding how to optimize cell delivery and/or dosing. Unfortunately, methods for non-invasive tracking of transplanted cells in vivo are still limited.

Visualization of cells in vivo can be achieved by using different molecular imaging modalities such as magnetic resonance imaging (MRI), radionuclide imaging (positron emission tomography (PET), single-photon emission computed tomography (SPECT)) and optical imaging. ${ }^{[10,11]}$ Although none of these imaging techniques is optimal, MRI is still the preferred imaging modality for visualization of exogenously delivered cells, because of its non-destructive and non-invasiveness, deep penetration and high spatial resolution. ${ }^{[12]}$

The most commonly used imaging agents for MRI application are superparamagnetic ironoxide nanoparticles (SPIONs), which were introduced several decades ago and have become a part of daily clinical routine use such as in imaging liver metastasis. SPIONs are nanoscaled 


\section{WILEY-VCH}

$83(5-15 \mathrm{~nm})$ crystals that consist of the biodegradable iron oxides magnetite $\left(\mathrm{Fe}_{3} \mathrm{O}_{4}\right)$ or maghemite $\left(\gamma-\mathrm{Fe}_{2} \mathrm{O}_{3}\right)$ or a mixture of both phases and exhibit magnetism only under the influence of an external magnetic field (superparamagnetism). ${ }^{[13]}$ In MRI, SPIONs exhibit a negative enhancement on $\mathrm{T} 2-$ and $\mathrm{T} 2 *$ weighted sequences, thus generating a signal change that is several magnitudes stronger compared to other contrast agents (e.g. gadolinium). ${ }^{[14]}$ To improve colloidal stability, solubility, and biocompatibility, SPIONs are coated with polymers such as dextran. ${ }^{[15]}$

Most previous studies on cellular tracking of MSCs used commercially available dextran- or carboxydextran-coated SPIONs (Endorem/Feridex or Resovist, respectively). ${ }^{[16-22]}$ However, manufacturing of both products was discontinued in 2008 and 2009, which prevents their future applications. But more importantly, these nanoparticles were originally developed to be taken up by phagocytic cells from the reticuloendothelial system (e.g. monocytes, macrophages and osteoclasts) but not by non-phagocytic cells such as MSCs. To overcome this limitation, transfection agents (TA) were used. ${ }^{[23]}$ However, some TAs are reported to be toxic under certain circumstances and their influence on MSCs biology is an issue of debate. ${ }^{[19,24-26]}$ In addition, the colloidal stability of dextran- or carboxydextran-coated SPIONs is impaired in cell culture media, making in vitro labeling difficult. ${ }^{[27]}$ Furthermore, the dextran-coating itself raises problems as it is susceptible to lysosomal degradation, resulting in exposure of cellular compartments and the cytosol to uncoated iron oxide nanoparticles and ions causing cytotoxic effects. ${ }^{[27,28]}$ Therefore, it is necessary to develop SPIONs with non-toxic coatings that meet the physiochemical need for efficient cellular uptake by MSCs in vitro.

In recent years, several studies focused on the development of novel SPION-coatings for MSC-labeling. ${ }^{[28-33]}$ Unfortunately, most of the previous studies suffer from missing information on either one or more of the following aspects: (1) characterization of the physiochemical properties of SPIONs, (2) exclusion of SPION-interference with the applied 


\section{WILEY-VCH}

109 methods (especially fluori- and colorimetric toxicity assays), (3) proof of SPIONinternalization, (4) information on the correct dosimetry, which includes not only the

111 administered, but also the delivered and effective cellular dose, (5) analysis of possible secondary effects introduced by SPIONs on MSC beyond their key characteristics and (6) the

113 proof of principle for MRI visualization of SPION-labeled MSCs in vitro and in vivo. It is

114 thus difficult to accurately interpret the results and compare them between different studies.

115

116 In this study, we describe a novel approach to address the above-mentioned challenges. Our

117 aim was to label MSCs with amino-polyvinyl alcohol coated SPIONs (A-PVA-SPIONs) and

118 to find a balance between cellular uptake without TAs for MRI visualization and low

119 toxicity/impact on MSC cellular functionality. In particular, we aim (1) to develop an efficient

120 A-PVA-SPION-labeling procedure for MSCs based on particle internalization, (2) to analyze

121 the influence of A-PVA-SPIONs on MSC viability, proliferation, adipogenic, osteogenic and

122 chondrogenic differentiation as well as migration and (3) to provide proof of principle for

123 visualization of A-PVA-SPION-labeled MSCs in MRI in vitro by using MRI-phantoms and in

124 vivo by using animal models. We hypothesize that A-PVA-SPIONs are suitable to label

125 MSCs without provoking cytotoxicity allowing their visualization and monitoring in MRI. 


\section{WILEY-VCH}

\section{Results}

\subsection{Development of an efficient A-PVA-SPION-labeling procedure for MSCs}

Developing an efficient A-PVA-SPION labeling procedure is crucial for subsequent visualization of MSCs in MRI and requires information about the nanoparticles physiochemical properties. For example, the extent to what nanoparticles are internalized by cells is determined by characteristics like size and surface charge, i.e. hydrodynamic diameter and Zeta potential. ${ }^{[15]}$ Furthermore, the size of the nanoparticle is needed for dosimetry calculations and for correct identification when confirming internalization by nanoscaleresolution imaging methods. The physiochemical properties of polymer coated SPIONs can change in response to $\mathrm{pH}$ (i.e. osmotic swelling) and protein concentration (i.e. formation of protein corona). ${ }^{[49]}$ It is thus important to thoroughly characterize the A-PVA-SPIONs under conditions that are identical to the read-out experiments. ${ }^{[50]}$ Therefore, we characterized size and surface charge of A-PVA-SPIONs not only in their solvent $\left(\mathrm{HNO}_{3} 10 \mathrm{mM}, \mathrm{pH} 2\right)$ but also in cell culture media (physiological $\mathrm{pH}$ 7.4) with and without fetal calf serum (FCS) supplementation. The iron oxide crystal mean diameter was $7.2 \pm 2.5 \mathrm{~nm}$ (Figure S1Figure 1). The SPIONs hydrodynamic diameter measures $14 \pm 2 \mathrm{~nm}$ for the uncoated and $25 \pm 3 \mathrm{~nm}$ for the A-PVA-coated SPION in its solvent $\mathrm{HNO}_{3}(10 \mathrm{mM}, \mathrm{pH} 2)$. The Zeta potential of the uncoated SPIONs is at $26 \pm 2 \mathrm{mV}$ and slightly decreases to $20 \pm 2 \mathrm{mV}$ when the A-PVAcoating is added. When transferred into FCS-free DMEM, the A-PVA-SPIONs hydrodynamic diameter increases to $42 \pm 2 \mathrm{~nm}$, in the presence of FCS to $45 \pm 2 \mathrm{~nm}$. The addition of FCS to the cell culture media results in a negative shift in the Zeta potential of A-PVA-SPIONs from $21 \pm 5 \mathrm{mV}$ to $-25 \pm 5 \mathrm{mV}$ (summarized in Table S1Table 1). Both, the increased hydrodynamic diameter and the negative zeta potential confirm the adsorption of proteins. ${ }^{[51]}$ In conclusion, we now expect intracellular A-PVA-SPIONs with a diameter of $42 \pm 2 \mathrm{~nm}$ to $45 \pm 2 \mathrm{~nm}$ in the following experiments proving their internalization. In addition, the 


\section{WILEY-VCH}

156 determined size of $45 \pm 2 \mathrm{~nm}$ will be the basis for calculating the A-PVA-SPIONs colloidal

157 behavior that is needed for establishing a dosimetry (details see Table S1).

158 We then investigated whether A-PVA-SPIONs are internalized by MSCs without any external

159 support such as transfection agents or magnetic fields. To confirm cellular internalization, we

160 used methods beyond Prussian Blue staining that allow resolution in the nanoscale:

161 transmission electron microscopy (TEM) and transmission X-ray microscopy (TXM). For this

162 purpose, MSCs were incubated for four hours with A-PVA-SPIONs $\left(100 \mu \mathrm{g}_{\mathrm{Fe}} / \mathrm{ml}\right)$ under serum-deprived conditions, which is known to be beneficial for efficient internalization. ${ }^{[53]}$ The qualitative assessment of A-PVA-SPION internalization was facilitated by TEM and TXM. TEM revealed that A-PVA-SPIONs are internalized by MSCs and stored in intracellular vesicles (mean vesicle diameter: $357 \pm 68.4 \mathrm{~nm}$ ) (Figure 2). TXM supported these findings (mean vesicle diameter: $387 \pm 48.4 \mathrm{~nm}$ ) and provided additional information that A-PVA-SPIONs are also found in smaller high contrast spheres (mean sphere diameter: $52 \pm 9.2 \mathrm{~nm}$ ), clusters of irregular shape, and a micron-sized cluster (length: $2000 \mathrm{~nm}$; width: $291 \mathrm{~nm}$ ) in the cytoplasm (Figure 3 and see also Video S1).

171 After having proven that A-PVA-SPIONs are internalized by MSCs, we sought experimental 172 conditions to optimize their cellular dose and define the corresponding dosimetry. Reporting a comprehensive dosimetry that consists of the administered, delivered and cellular dose is crucial for the establishment of a correct dose-response relationship. ${ }^{[53]}$ The administered dose itself only describes the amount of nanoparticles that was employed at the beginning of the experiment. A more relevant metric is described by the delivered dose that also takes the

177 particles colloidal behavior and the exposure time into account and gives thus information 178 about the amount of particles that reaches the cell monolayer. ${ }^{[34]}$ Finally the cellular dose can 179 be determined experimentally and describes the amount of A-PVA-SPIONs internalized by 180 the cells. For this, MSCs were incubated with varying concentrations of A-PVA-SPIONs 181 (administered dose) and the corresponding cell-bound iron (cellular dose) was determined. 


\section{WILEY-VCH}

182 After four hours, the value for cell-bound iron reaches $5.9 \pm 2.5 \mathrm{pg}_{\mathrm{Fe}} /$ cell at the lowest

183 administered dose $(50 \mu \mathrm{g} \mathrm{Fe} / \mathrm{ml})$, which does not further increase significantly at higher

184 administered doses. The TA Protamine had no beneficial effect (ANOVA, $\mathrm{p}=0.126$ ) on this

185 pattern (Figure 4A). However, when incubation time was extended to 24 hours, an increase of 186 cell-bound iron was observed (ANOVA, $\mathrm{p}=0.014$ ). After 24 hours, the cell-bound iron 187 increases to $8.2 \pm 3.6 \mathrm{pg}_{\mathrm{Fe}} /$ cell at the lowest administered dose $\left(50 \mu \mathrm{g}_{\mathrm{Fe}} / \mathrm{ml}\right)$, which is again not 188 affected by increasing the administered dose (Figure 4B). For accurate interpretation of the 189 results and comparability with other studies, a summary of the particle dosimetry results is

190 given in Table 2. In summary, we found that an optimized cellular dose in MSCs is reached at 191 A-PVA-SPION-labeling for $4 \mathrm{~h}$ under serum-deprived conditions followed by $20 \mathrm{~h}$ under 192 standard MSC culture conditions without the need of additional Protamine as TA.

193

\subsection{Non-toxic A-PVA-SPIONs stimulate MSCs migration}

When using A-PVA-SPIONs for MSC-labeling in cell-based therapy approaches, compromising effects on MSC survival and function have to be avoided. We thus investigated viability, multilineage differentiation and migration of MSCs after A-PVA-SPION-labeling

198 with four different administered doses ranging from 0 to $100 \mu \mathrm{g}_{\mathrm{Fe}} / \mathrm{ml}$.

Viability and proliferation of A-PVA-SPION-labeled MSCs was assessed after four and eight days and found to be unaffected compared to unlabeled MSCs (Figure 5). Notably, the amount of cell bound iron is below the critical value that leads to interference with these assays (Figure S2 and Information S3). Differentiation of A-PVA-SPION-labeled MSCs towards the adipogenic, osteogenic, and chondrogenic phenotype was achieved without differences to their respective controls (Figure 6). Migration was analyzed in a modified wound scratch assay. A-PVA-SPION-labeled MSCs exhibit an increase in migration rate compared to unlabeled controls (Figure 7 and Video S2 and S3). Quantitative analysis revealed that this effect reaches statistical significance at the highest analyzed A-PVA-SPION 


\section{WILEY-VCH}

208 concentration $\left(50 \mu \mathrm{g}_{\mathrm{Fe}} / \mathrm{ml} v\right.$ s. control: $\mathrm{p}=0.069 ; 100 \mu \mathrm{g}_{\mathrm{Fe}} / \mathrm{ml}$ vs. control: $\mathrm{p}=0.001$; Figure 7$)$.

209 Our results show that A-PVA-SPION-labeling does not affect differentiation, a key function

210 of MSCs as defined by The International Society for Cellular Therapy (ISCT), but rather

211 stimulates their migratory behavior. ${ }^{[35]}$

\subsection{A-PVA-SPION-labeled MSCs can be visualized in MRI in vitro and in vivo}

214 We found that labeling of MSCs with A-PVA-SPIONs had no negative effects on their viability or regenerative and therefore we investigated whether the amount of cell-bound iron was sufficient for visualization of A-PVA-SPION labeled MSCs using MRI in vitro and in vivo. To this end, cell phantoms with different numbers of A-PVA-SPION-labeled MSCs were prepared and scanned by MRI using T2 STIR and T1 VIBE sequences. A small effect could be seen using both sequences where a signal loss due to the A-PVA-SPION labeled MSCs was detected only at the highest cell concentration on the transverse plane of the MR images (Figure 8A). Acquisition of the orthogonal plane showed that the cells were concentrated at the bottom of the wells (data not shown). However, due to the small depth of the gel, which was lower than the minimum slice thickness available, the meniscal 'partial volume' effect precluded any quantification. Cell distribution was not homogenous enough to determine a precise effect of cell number on $\mathrm{T} 1$ and $\mathrm{T} 2$ star relaxation times. Nonetheless, the phantom results showed a trend in effect on T2 and indicated that MSC labeling was efficient for MRI visualization with the sequences used.

In vivo, A-PVA-SPION induced signal loss was detectable on T1 weighted (VIBE) MR 229 images as a black region superior and anterior to the lower section of the femur 24 hours after 230 the injection of the A-PVA-SPION-labeled MSCs into the right naïve knee joint of Lewis rats 231 (Figure 8B I, III). No signal could be seen at the region on VIBE MR images of the left knee 232 joint where non-labeled MSCs were injected (Figure 8C I and III). These findings were 233 confirmed using corresponding dUTE MR images where A-PVA-SPION-labeled MSCs result 


\section{WILEY-VCH}

234 in positive MR enhancement and can be seen as a white region at the same position which is 235 absent in controls (Figure 8B II, IV and 8C II, IV). Post mortem histology of the animal's 236 knee joints confirmed the presence of A-PVA-SPION labeled MSCs (Figure S3).

237

238 


\section{WILEY-VCH}

\section{Discussion}

Our aim in this study was to develop an efficient labeling procedure for human MSCs with APVA-SPIONs bypassing detrimental secondary effects on MSC viability and functions and verifying the feasibility of visualizing A-PVA-SPION-labeled MSCs in MRI.

\subsection{Development of an efficient labeling procedure}

A major advantage of PVA is the fact that it is biocompatible and safe to use in humans as it has been in medical use for several years, such as for cartilage replacements, wound packing and contact lenses. ${ }^{[54]}$ A-PVA-SPIONs are already well characterized for their physiochemical and magnetic properties. ${ }^{[55]}$ In contrast to dextran- or carboxydextran-SPIONs, they exhibit excellent colloidal stability and dispersion in different cell culture media in vitro even in the presence of fetal calf serum $(\mathrm{FCS}) .{ }^{[52]}$ The amine-functionalization promotes A-PVA-SPION internalization by non-phagocytic cells without the need for compromising TAs, which also applies for primary human cells such as MSCs as proven in our study. ${ }^{[38,56,57]}$

Evidence of the internalization of A-PVA-SPIONs by MSCs and their subcellular location was provided by both TEM and TXM approaches. The advantages of the TXM approach over methods used in other studies are artifact-free sample preparation of the MSCs, visualization in the nanometer range and 3D spatial information, i.e. conclusive evidence of cellular internalization. The TEM approach showed A-PVA-SPIONs as high contrast particles that accumulate in intracellular vesicles. The TXM data confirmed this result, but also demonstrated that smaller high contrast spheres and irregular shaped clusters can be found. The size of these small high contrast spheres analyzed by TXM is similar to the size of APVA-SPIONs in DMEM + FCS determined by PCS (TXM: $52.9 \pm 9 \mathrm{~nm}$ vs. PCS: $45 \pm 2 \mathrm{~nm}$ ). We thus assume that single A-PVA-SPIONs are either internalized individually or are a result of endosomal escapes. So far, we cannot distinguish whether the single A-PVA-SPIONs are either vesicle-bound or freely dispersed in the cytosol. Vesicle-bound single particles would 


\section{WILEY-VCH}

265 indicate that A-PVA-SPIONs enter via a typical endocytosis-exocytosis route by being

266 internalized as individual nanoparticles and further sorted into bigger vesicles like lyso- or exosomes. ${ }^{[58]}$ Freely dispersed A-PVA-SPIONs could directly interact with constituents of the cytosol, i.e. proteins, mRNA, and cellular organelles, which may be other avenues of A-PVASPION-induced functional changes. However, further research is needed to provide conclusive evidence for one of those assumptions. Quantitative assessment of the cellular

271 dose revealed that a higher amount of cell-bound iron can be achieved by prolonging the 272 incubation time, but not by increasing the administered dose above $50 \mu \mathrm{g}_{\mathrm{Fe}} / \mathrm{ml}$. Similar results 273 were already observed for the internalization of PVA-SPIONs by non-phagocytic cell lines. ${ }^{[38,}$

$274{ }^{57]}$ These results point towards an active uptake mechanism, which is energy dependent as recently suggested. ${ }^{[52]}$ A more detailed discussion of the dosimetry can be found in Information S4.

\subsection{Analysis of possible secondary effects}

For MSC tracking approaches in vivo, it is important that those A-PVA-SPIONs are not only non-toxic, but also do not interfere with the cells' regenerative functions. Therefore, we first

281 focused on proliferation and multi-lineage differentiation both are key functions of MSCs as defined by The International Society for Cellular Therapy (ISCT). ${ }^{[35]}$

In our study, we observed no signs of A-PVA-SPION-induced toxicity as proliferation and mitochondrial activity were unchanged similar to results observed for other cells. ${ }^{[52,57]}$ Next, the MSCs' ability to differentiate into the adipogenic, osteogenic and chondrogenic lineage was investigated and was found to be unchanged. These positive results are noteworthy since

287 a number of studies reported impaired chondrogenesis after SPION-application. ${ }^{[18,19,25,59]}$ 288 Only two of these publications report the corresponding cellular doses that were higher than 289 the one determined in our study; $25.7 \pm 0.96 \mathrm{pg}_{\mathrm{Fe}} /$ cell and $13-16 \mathrm{pg}_{\mathrm{Fe}} / \mathrm{cell}^{\left[19,{ }^{25]}\right.}$ The 290 impairment of chondrogenesis might thus be caused by a high intracellular iron load as 


\section{WILEY-VCH}

291 already hypothesized. ${ }^{[18,25]}$ It can be thus assumed that the cellular dose of $8.2 \pm 3.6 \mathrm{pg} / \mathrm{cell}$ in

292 our study is below a critical threshold that leads to impaired chondrogenesis.

293 A number of in vivo studies provide evidence that exogenously delivered MSCs migrate and

294 target specific tissues via an active mechanism. For example, when injected into femurs

295 MSCs were later detected in the contralateral bone or MSCs implanted into the tibial bone

296 marrow cavity were detected in the callus of the ulnar fracture site after three weeks. ${ }^{[60,61]}$

297 Three days after injection into the tail-vein MSCs were detected at the fracture site. ${ }^{[62]}$

298 Interestingly, in our study, migration of MSCs is increased after labeling with A-PVA-

299 SPIONs. This effect could be advantageous in the context of cell-based therapies as

300 exogenously delivered MSCs might migrate better in vivo. On the other hand, this effect could

301 also be disadvantageous as it indicates cellular changes by A-PVA-SPIONs in MSCs that

302 could influence so-far unknown parameters beyond migration. Future studies are needed to 303 determine if the change in migration upon A-PVA-SPION-labeling has consequences for the 304 outcome of MSC-based therapies. 


\section{WILEY-VCH}

\section{Conclusion}

SPION-labeling in combination with MRI is still the most promising approach for in vivo visualization of exogenously delivered cells and has gained high interest in cell-based therapies using MSCs. In the current study, we characterized the physiochemical properties of A-PVA-SPIONs, investigated their interference with viability assays and their internalization by human MSCs, report a correct dosimetry, found no impact on MSC viability and differentiation, but enhanced migration, and finally provided the proof of principle for MRI visualization of A-PVA-SPION-labeled MSCs in vitro and in vivo. The current study thus provides comprehensive information about the impact of A-PVA-SPIONs on MSCs and the feasibility of MRI visualization. In summary, the A-PVA/PVA copolymer has proven to be a suitable SPION-coating used for MSC labeling. What remains unknown is the particles' longterm fate with respect to MRI visualization of A-PVA-SPION labeled MSCs. For example, the accuracy of MRI data in vivo is compromised by the inability to distinguish signals (1) from viable and dead cells, (2) from internalized and excreted SPIONs and (3) from SPIONs and MSCs engulfed by macrophages. Another concern is the A-PVA-SPIONs metabolism within the body that is determined by its stability in vivo. Future work should therefore focus on research addressing 1) the A-PVA-SPIONs' retention time in the cell and elucidation of the involved endo- and exocytosis mechanisms and 2) whether the A-PVA-coating separates from the iron core resulting in renal excretion of A-PVA and integration of the SPION's iron in the body's iron metabolism. Taken together, these data help to develop A-PVA-SPIONbased MRI-tracking of MSCs towards a reliable research tool where non-invasiveness, deep penetration, and high spatial resolution are needed. Thereby, it might be possible to gain further insight into the spatial and temporal distribution of transplanted MSCs in tissue repair and thus to optimize cell-based therapies. 
WILEY-VCH

334 


\section{WILEY-VCH}

\section{Experimental Section}

SPION synthesis and A-PVA surface modification: A-PVA-SPION. SPIONs were synthesized following a co-precipitation protocol. ${ }^{[36,37]}$ Briefly 0.064 moles of iron II from $\mathrm{FeCl}_{2}$ and 0.128 moles of iron III from $\mathrm{FeCl}_{3}$ were solved in $1.5 \mathrm{~L}$ deionized (DI) water and mixed with $120 \mathrm{~mL}$ of an $\mathrm{NH}_{4} \mathrm{OH}$ solution (25\%). After 10 min the suspension was sedimented under a magnetic field and washed with DI water until $\mathrm{pH}$ 7. SPIONs were redispersed in $400 \mathrm{~mL}$ and oxidized with $160 \mathrm{~mL} \mathrm{HNO}_{3}(2 \mathrm{M})$ and $240 \mathrm{~mL} \mathrm{Fe}\left(\mathrm{NO}_{3}\right)_{3}(0.35 \mathrm{M})$ under reflux for $1.5 \mathrm{~h}$ to achieve maghemite $\left(\gamma-\mathrm{Fe}_{2} \mathrm{O}_{3}\right)$. The suspension was washed again with DI water and was dialyzed (with MWCO 12-14 $\mathrm{kDa}$ cellulose membrane dialysis tubing) against $\mathrm{HNO}_{3}$ $(10 \mathrm{mM})$ for 3 days by changing the solution every $12 \mathrm{~h}$. The suspension was finally centrifuged at $30000 \mathrm{~g}$ for $15 \mathrm{~min}$ and the supernatant was kept. The final suspension of SPION had a concentration of $10 \mathrm{mg}_{\mathrm{Fe}} / \mathrm{mL}$ and a $\mathrm{pH}$ of approximately 2 . Surface modification of the SPION with PVA was done following a protocol described previously. ${ }^{[36,38,39]}$ PVA$\mathrm{OH}$ (10 wt\%; Mowiol 3-85, Kuraray Europe GmbH) and A-PVA (2 wt \%; M12, Erkol.) solutions were prepared by dissolving dry PVA in ultrapure DI water and the solutions were rapidly heated for 1 hour at $90^{\circ} \mathrm{C}$, cooled down, filtered at $0.45 \mu \mathrm{m}$ with a PTFE filter syringe and stored at $4{ }^{\circ} \mathrm{C} .10$ volumes of naked SPION were mixed with 9 volumes of PVA-OH solution (100 mg PVA OH/mL) and 1 volume of A-PVA solution (20 mg A-PVA/mL). The final A-PVA-SPION suspension $\left(5 \mathrm{mg}_{\mathrm{Fe}} / \mathrm{mL}, \mathrm{pH} 3\right)$ was stored at least 1 week at $4^{\circ} \mathrm{C}$ before further use.

A-PVA-SPION characterization: Crystallite's size was measured by counting of 400 crystallites sizes on Transmission Electron Microscopy (TEM CM12; FEI Co. Philips Electron Optics, Zürich, Switzerland) pictures. Hydrodynamic diameters and Zeta potential of A-PVA-SPIONs were measured on a Photon Correlation Spectroscopy apparatus (PCS 


\section{WILEY-VCH}

ZetaPals from Brookhaven: Laborchemie GES.M.B.H., Vienna, Austria). Uncoated SPIONs and A-PVA-SPION suspension were investigated by Fourier Transformation InfraRed spectroscopy (FTIR) showing the characteristic vibration bands for $\gamma$-Fe2O3 and A-PVA (Figure S1 and Information S2).

Human MSC isolation, cultivation and functional analysis: This study was approved by the local ethical committee; all donors gave informed written consent. Primary human MSCs were isolated from bone marrow of human donors ( 8 male, mean age: $59 \pm 9.1$ years; 7 female, mean age: $60 \pm 16.6$ years) undergoing hip surgery as described previously. ${ }^{[40]}$ The “culture medium” was Dulbecco’s modified Eagle's medium (DMEM; Low Glucose, Gibco, Grand Island, NY) with 10\% fetal calf serum (FCS; Biochrom AG, Berlin, Germany), 5mM L-alanyl-L-glutamine (Gibco, Grand Island, NY), $100 \mathrm{U} / \mathrm{mL}$ penicillin plus $100 \mu \mathrm{g} / \mathrm{mL}$ streptomycin. Cells were counted by using CasyTT for standard cell culture (Schärfe Systems, Reutlingen, Germany) or a Neubauer chamber (C-Chip, Peqlab, Erlangen, Germany) when only small volumes of cells were available. All experiments described in this section where performed with cells from $\mathrm{n}=5$ individual donors.

Proliferation rates were assessed by using a CyquantNF® Cell Proliferation assay kit (Life Technologies, Carlsbad, CA, United States). Cell viability was assessed using PrestoBlue® (Life Technologies, Carlsbad, CA, United States) as described earlier. ${ }^{[41]}$ Briefly, 2000 MSCs $/ \mathrm{cm}^{2}$ were seeded into 48-well plates and measured after one (d1), four (d4) and eight (d8) days of culture. CyquantNF® values from $\mathrm{d} 4$ and $\mathrm{d} 8$ were normalized to $\mathrm{d} 1$. PrestoBlue ${ }^{\circledR}$ values were normalized to cell number determined by CyquantNF®. All measurements were performed in triplicates using a multimode microplate reader (m200 pro, Tecan).

Osteogenic differentiation of $2.4 \times 10^{4}$ MSCs per 24-well was induced by supplementing culture media with $200 \mu \mathrm{M}$ ascorbic acid, $7 \mathrm{mM}$ ß-glycerol phosphate, $0.01 \mu \mathrm{M}$ 


\section{WILEY-VCH}

dexamethasone for $13 \mathrm{~d}$. The calcified matrix was visualized by Alizarin Red S (AR) and quantified photometrical by dissolving AR in $10 \%$ cetylpyridinium chloride (readout wavelength at $\lambda=562 \mathrm{~nm}$ ). Adipogenic differentiation was induced by supplementing culture media with $1 \mu \mathrm{M}$ dexamethasone, $2 \mu \mathrm{M}$ insulin, $200 \mu \mathrm{M}$ indomethacin, $500 \mu \mathrm{M}$ isobutylmethyl-xanthin for $14 \mathrm{~d}$. Fatty acids were detected by OilRed $\mathrm{O}$ staining and quantified photometrical by dissolving in $100 \%$ isopropanol (readout wavelength at $\lambda=500 \mathrm{~nm}$ ). Each experiment was conducted in triplicate. Chondrogenesis was induced by stimulating a pellet culture $\left(3 \times 10^{5}\right.$ cells/pellet) with FCS-free culture media plus $10 \mathrm{ng} / \mathrm{mL}$ TGF- $\beta 1,10-7 \mathrm{M}$ dexamethasone, $50 \mu \mathrm{g} / \mathrm{mL}$ ascorbic acid, $40 \mu \mathrm{g} / \mathrm{mL}$ proline, $100 \mu \mathrm{g} / \mathrm{mL}$ pyruvate, $6.25 \mu \mathrm{g} / \mathrm{mL}$ ITS, $1.25 \mathrm{mg} / \mathrm{mL}$ BSA, $5.35 \mathrm{mg} / \mathrm{mL}$ linoleic acid) for $21 \mathrm{~d}$ and detected by Alcian Blue staining and quantification of proteoglycan as described elsewhere with the modification for pellet cultures and optimized read out wavelength $(\lambda=516 \mathrm{~nm}) .{ }^{[42]}$

Migration was analyzed in culture inserts for self-insertion (IBIDI, Munich, Germany) in duplicate. $8 \times 10^{3}$ cells were allowed to attach for $5 \mathrm{~h}$ in each cavity of the insert prior to insert removal and addition of culture media with $5 \mu \mathrm{g} / \mathrm{ml}$ Mitomycin C (Sigma-Aldrich, St. Louis, USA). Migration into the defined cell free gap $(500 \mu \mathrm{m})$ was observed for $24 \mathrm{~h}$ under an inverted microscope (DMI6000B, Leica, Germany) with a live cell imaging system, taking images every $20 \mathrm{~min}$. Assay analysis (area covered by cells) was performed with Tscratch. ${ }^{[43]}$

A-PVA-SPION-labeling of MSCs and A-PVA-SPION dosimetry: Prior use, A-PVA-SPIONs underwent sonication for $1 \mathrm{~min}$ and $\mathrm{pH}$-adjustment to neutral range (7.2 - 7.6). Adherent MSCs (80-90\% confluence) were washed with PBS and incubated with A-PVA-SPION containing FCS-free culture media for $4 \mathrm{~h}(\mathrm{n}=4)$ with fixed media height $(1.3 \mathrm{~mm})$ throughout different culture vessels to prevent variations in the administered dose. Protamine was used at a final concentration of $5 \mu \mathrm{g} / \mathrm{ml}(\mathrm{n}=2)$. If MSCs were labeled for $24 \mathrm{~h}(\mathrm{n}=2), 10 \%$ FCS was added after $4 \mathrm{~h}$ for sufficient cell nutrition. Finally, A-PVA-labeled MSCs were washed 6x 


\section{WILEY-VCH}

413 with PBS before further use. For dosimetry calculations, we used a simplified model based on

414 In vitro Sedimentation, Diffusion and Dosimetry model (ISDD) developed by Hinterliter et al.,

415 taking additive transport by diffusion and sedimentation into account. ${ }^{[44]}$ The error compared

416 to the ISDD model is reasonably small compared to all the uncertainty arising from the in

417 vitro agglomeration and formation of the protein corona, both influencing the diameter and

418 density of the particles. The characteristic properties of the particles used for the calculation

419 of the dose delivered to the cell surface are summarized in Table S2.

Determination of cell-bound iron: After centrifugation at 400xg, the cell pellet was dried overnight at $50^{\circ} \mathrm{C}$, re-suspended in $125 \mu 16 \mathrm{~N} \mathrm{HCL}$ followed by a second overnight incubation step at $50^{\circ} \mathrm{C}$. $25 \mu \mathrm{l}$ sample was then mixed with $25 \mu \mathrm{l} 6 \mathrm{~N}$ HCL followed by adding $50 \mu 1$ of $5 \%$ $\mathrm{K}_{4}\left[\mathrm{Fe}(\mathrm{CN})_{6}\right]$ (Merck, Darmstadt, Germany). After 20min, absorbance was read at 690nm (m200 pro, Tecan, Männedorf, Switzerland) against a standard curve using $\mathrm{FeCl}_{3}$. Each measurement was carried out in quadruplicate. To obtain cell bound iron, iron $\left(\mathrm{pg}_{\mathrm{Fe}} / \mathrm{cell}\right)$ was normalized to total cell number (average of $2 \times 10^{6}$ cells).

Transmission electron microscopy (TEM) and Transmission X-ray microscopy (TXM):. For

TEM, $5 \times 10^{5}$ MSCs were trypsinized and further processed as described previously ${ }^{[45]}$. After

431 fixation and prior embedding, fixed cells were centrifuged for pellet formation. The mean 432 vesicle size was determined by measuring the diameter of $n=4$ vesicles from one 433 representative TEM micrograph using ImageJ Software. ${ }^{[46]}$

434 For TXM, MSC were cultivated for $24 \mathrm{~h}$ on gold grids (type HZB-2, Gilder Grids, Grantham, 435 UK) coated with a perforated carbon film (Quantifoil Micro Tools GmbH, Jena, Germany) 436 prior to A-PVA-SPION-labeling. Samples were then plunge frozen in liquid ethane and 437 transferred into liquid nitrogen. Data acquisition using the HZB TXM at the undulator 438 beamline U41-FSGM, electron storage ring BESSY II, Berlin, was performed as described 


\section{WILEY-VCH}

439 previously. ${ }^{[47]}$ For imaging, a zone plate objective with $25 \mathrm{~nm}$ outermost zone width was used.

440 The tilt range of the sample was from $-60^{\circ}$ to $+60^{\circ}$. For tomographic reconstruction of the 441 acquired Tilt series eTomo was used and visualized using CTvox (CTvox 2.6, Bruker CT, 442 Kontich, Belgium) for 3D remodeling of the volumetric data. ${ }^{[48]}$ The mean diameter of 443 vesicles and high contrast spheres was determined from seven representative images of the 444 tomograms z-stack using Image J Software (vesicles measured: n=9; high contrast spheres 445 measured: $\mathrm{n}=80$ ).

Visualization by MRI in vitro (phantoms) and in vivo (animals): Female Lewis rats were obtained from Janvier Labs (Cedex, France). The rats weighed between 150 and 175g and were 6-8 weeks old on arrival. They were housed in the animal facility at the University of

450 Geneva under pathogen-free conditions in standard cages and were fed standard diet and water ad libitum. Animal handling was in accordance with guidelines of the Swiss Committee Committee at the University of Geneva (authorization no.1049/3580/3). MSC labeling was performed as described. A-PVA-SPION-labeled $\left(100 \mu \mathrm{g}_{\mathrm{Fe}} / \mathrm{ml}\right)$ MSCs were trypsinized, counted, and fixed in $4 \%$ formaldehyde (Roth, Karlsruhe, Germany). Increasing numbers of fixed cells were spun down and embedded in $200 \mu 13 \%(\mathrm{w} / \mathrm{v})$ gelatine on a 48 -well plate. The cell phantoms were scanned using the same sequences as optimized for in vivo imaging and a $15 \mathrm{~cm}$ surface for homogeneous signal response. The experiment was carried out on $1.5 \mathrm{~T}$ scanner. Longer scan times (10 signal averages) were needed to regain the SNR lost going to 460 a larger coil and lower field.

461 The MR imaging parameters for the phantoms are as followed: A 'T2-weighted' 2D 462 acquisition with TR/TE/TI 8640/44/160ms, Flip angle $160^{\circ}$, Resolution $0.26 \mathrm{~mm}$, FOV $463200 * 100 \mathrm{~mm}$ and slice thickness $1 \mathrm{~mm}$. The 'T1-weighted' gradient echo is a 3D acquisition 


\section{WILEY-VCH}

464 with resolution of $0.35 \mathrm{~mm}$ and slice thickness $0.2 \mathrm{~mm}$,TR/TE $22 / 9.5 \mathrm{~ms}$, Flip angle $10^{\circ}$ and 465 FOV $160 * 80 \mathrm{~mm}$.

466 For in vivo visualization of labelled cells, the A-PVA-SPION-labeled MSCs and the non467 labelled MSCs were injected intra-articularly into the right and left naïve knee joints of Lewis 468 rats (Janvier Labs, Cedex, France) respectively. The following day, MR imaging of rat knee 469 joints in vivo was conducted using a Siemens Magnetom® ${ }^{\circledR}$ Trio 3T clinical scanner. A 470 standard $4 \mathrm{~cm}$ loop coil and respiratory monitoring with a pressure pad were used during the 471 imaging session. The imaging protocol begins with a standard low-resolution localization 472 sequence and the isotropic resolution 3D Ultra-short Echo time (UTE) double echo MR 473 sequence fixed orthogonal and at the magnet centre. This was subsequently used to localize 474 the correct plane for the $2 \mathrm{D}$ or thinner slab 3D images as well as for quantitative analysis. The 475 protocol parameters of the sequences used were as follows: 3D T1 gradient echo was used to detect and visualize A-PVA-SPIONs by signal loss.

477 Parameters: TR/TE $14.3 / 5.9 \mathrm{~ms}$, flip angle $12^{\circ}$, fat suppression, isotropic resolution $0.31 \mathrm{~mm}$, 478 and FOV 100mm, acquisition time 4 minutes 54 seconds.

479 Difference Ultra-short Echo time imaging (dUTE) was used for A-PVA-SPION positive 480 contrast detection and quantification. Parameters: 3D isotropic matrix 448 and $80 \mathrm{~mm}$ FOV, 481 giving $180 \mu \mathrm{m}$ in all three dimensions, 50000 radial projections, UTE/TE(2) $0.07 \mathrm{~ms} / 2.46 \mathrm{~ms}$ 482 (for in-phase fat/water image), TR 9.6ms (in vivo 100 segments), flip angle $10^{\circ}$, acquisition 483 time 16 minutes 54 seconds.

Statistics: When performing multiple pair-wise comparisons, one-way or two-way analysis of variance (ANOVA) were performed, and p-values were adjusted using Bonferroni's p-value 487 adjustment multiple comparison procedure. Results are presented as mean \pm standard deviation (SD). P-values $<0.05$ were considered statistically significant. 


\section{WILEY-VCH}

490

491

492

493

494

495

496

497

498

499

500

501

502

503

504

\section{Supporting Information}

Supporting Information is available from the Wiley Online Library or from the author.

\section{Acknowledgements}

The research leading to these results has received funding from the European Union Seventh Framework Programme NMP-2008-4.0-1, GRANT AGREEMENT No 228929. We gratefully acknowledge Prof. Petra Knaus and P. Paarmann at the Institute for Chemistry and Biochemistry, Freie Universität Berlin for fruitful discussions and Petra Schrade at the Institute of Vegetative Anatomy, Charité - Universitätsmedizin, Berlin for performing the Transmission electron microscopy analysis. We thank A. Blankenstein, D. Jacobi, L. Schumann, M. Textor and Marie-Gabrielle Beuzelin for excellent technical assistance. MSCs were generously provided by the BCRT Core Unit Cell Harvesting. We thank HZB for the allocation of synchrotron radiation beamtime. We wish to confirm that there are no known conflicts of interest associated with this publication and there has been no significant financial support for this work that could have influenced its outcome.

Received: ((will be filled in by the editorial staff))

Revised: ((will be filled in by the editorial staff)) Published online: ((will be filled in by the editorial staff)) 


\section{WILEY-VCH}

513 [1] Prockop, D. J.; Kota, D. J.; Bazhanov, N.; Reger, R. L., Journal of cellular and molecular medicine 2010, 14 (9), 2190-9. DOI 10.1111/j.1582-4934.2010.01151.x.

[2] Preininger, B.; Duda, G.; Gerigk, H.; Bruckner, J.; Ellinghaus, A.; Sass, F. A.; Perka, C.; Schmidt-Bleek, K.; Dienelt, A., PloS one 2013, 8 (2), e52650. DOI 10.1371/journal.pone.0052650. [3] Krampera, M.; Pizzolo, G.; Aprili, G.; Franchini, M., Bone 2006, 39 (4), 678-83. DOI 10.1016/j.bone.2006.04.020.

[4] Chanda, D.; Kumar, S.; Ponnazhagan, S., Journal of cellular biochemistry 2010, 111 (2), 24957. DOI $10.1002 /$ jcb. 22701 .

[5] Chen, F. H.; Tuan, R. S., Arthritis research \& therapy 2008, 10 (5), 223. DOI 10.1186/ar2514. [6] Stamm, C.; Klose, K.; Choi, Y. H., Advances in biochemical engineering/biotechnology 2010, 123, 293-317. DOI 10.1007/10_2010_77.

[7] Naegele, J. R.; Maisano, X.; Yang, J.; Royston, S.; Ribeiro, E., Neuropharmacology 2010, 58 (6), 855-64. DOI 10.1016/j.neuropharm.2010.01.019.

[8] Chiu, A. Y.; Rao, M. S., Neurotherapeutics: the journal of the American Society for Experimental NeuroTherapeutics 2011, 8 (4), 744-52. DOI 10.1007/s13311-011-0066-9.

[9] Salem, H. K.; Thiemermann, C., Stem Cells 2010, 28 (3), 585-96. DOI 10.1002/stem.269.

[10] Bhirde, A.; Xie, J.; Swierczewska, M.; Chen, X., Nanoscale 2011, 3 (1), 142-53. DOI 10.1039/c0nr00493f.

[11] Tang, F.; Barbacioru, C.; Bao, S.; Lee, C.; Nordman, E.; Wang, X.; Lao, K.; Surani, M. A., Cell stem cell 2010, 6 (5), 468-78. DOI 10.1016/j.stem.2010.03.015.

[12] Schafer, R.; Kehlbach, R.; Muller, M.; Bantleon, R.; Kluba, T.; Ayturan, M.; Siegel, G.; Wolburg, H.; Northoff, H.; Dietz, K.; Claussen, C. D.; Wiskirchen, J., Cytotherapy 2009, 11 (1), 6878. DOI 10.1080/14653240802666043.

[13] Corot, C.; Robert, P.; Idee, J. M.; Port, M., Advanced drug delivery reviews 2006, 58 (14), 1471-504. DOI 10.1016/j.addr.2006.09.013.

[14] Gossuin, Y.; Gillis, P.; Hocq, A.; Vuong, Q. L.; Roch, A., Wiley interdisciplinary reviews. Nanomedicine and nanobiotechnology 2009, 1 (3), 299-310. DOI 10.1002/wnan.36.

[15] Gupta, A. K.; Gupta, M., Biomaterials 2005, 26 (18), 3995-4021. DOI 10.1016/j.biomaterials.2004.10.012.

[16] Schafer, R.; Ayturan, M.; Bantleon, R.; Kehlbach, R.; Siegel, G.; Pintaske, J.; Conrad, S.; Wolburg, H.; Northoff, H.; Wiskirchen, J.; Weissert, R., Cell transplantation 2008, 17 (8), 923-41. [17] Arbab, A. S.; Yocum, G. T.; Kalish, H.; Jordan, E. K.; Anderson, S. A.; Khakoo, A. Y.; Read, E. J.; Frank, J. A., Blood 2004, 104 (4), 1217-23. DOI 10.1182/blood-2004-02-0655.

[18] Kostura, L.; Kraitchman, D. L.; Mackay, A. M.; Pittenger, M. F.; Bulte, J. W., NMR in biomedicine 2004, 17 (7), 513-7. DOI 10.1002/nbm.925.

[19] Henning, T. D.; Sutton, E. J.; Kim, A.; Golovko, D.; Horvai, A.; Ackerman, L.; Sennino, B.; McDonald, D.; Lotz, J.; Daldrup-Link, H. E., Contrast media \& molecular imaging 2009, 4 (4), 165 73. DOI 10.1002/cmmi.276.

[20] van Buul, G. M.; Farrell, E.; Kops, N.; van Tiel, S. T.; Bos, P. K.; Weinans, H.; Krestin, G. P.; van Osch, G. J.; Bernsen, M. R., Contrast media \& molecular imaging 2009, 4 (5), 230-6. DOI 10.1002/cmmi.289.

[21] Ittrich, H.; Lange, C.; Togel, F.; Zander, A. R.; Dahnke, H.; Westenfelder, C.; Adam, G.; Nolte-Ernsting, C., Journal of magnetic resonance imaging : JMRI 2007, 25 (6), 1179-91. DOI 10.1002/jmri.20925.

[22] Vallee, J. P.; Hauwel, M.; Lepetit-Coiffe, M.; Bei, W.; Montet-Abou, K.; Meda, P.; Gardier, S.; Zammaretti, P.; Kraehenbuehl, T. P.; Herrmann, F.; Hubbell, J. A.; Jaconi, M. E., Stem cells translational medicine 2012, I (3), 248-60. DOI 10.5966/sctm.2011-0028.

[23] Frank, J. A.; Miller, B. R.; Arbab, A. S.; Zywicke, H. A.; Jordan, E. K.; Lewis, B. K.; Bryant, L. H., Jr.; Bulte, J. W., Radiology 2003, 228 (2), 480-7. DOI 10.1148/radiol.2281020638.

[24] Arbab, A. S.; Yocum, G. T.; Rad, A. M.; Khakoo, A. Y.; Fellowes, V.; Read, E. J.; Frank, J. A., NMR in biomedicine 2005, 18 (8), 553-9. DOI 10.1002/nbm.991.

[25] Bulte, J. W.; Kraitchman, D. L.; Mackay, A. M.; Pittenger, M. F., Blood 2004, 104 (10), 34102; author reply 3412-3. DOI 10.1182/blood-2004-06-2117. 


\section{WILEY-VCH}

566 [26] Balakumaran, A.; Pawelczyk, E.; Ren, J.; Sworder, B.; Chaudhry, A.; Sabatino, M.; Stroncek, D.; Frank, J. A.; Robey, P. G., PloS one 2010, 5 (7), e11462. DOI 10.1371/journal.pone.0011462.

[27] Singh, N.; Jenkins, G. J.; Asadi, R.; Doak, S. H., Nano reviews 2010, 1. DOI 10.3402/nano.v1i0.5358.

[28] Delcroix, G. J.; Jacquart, M.; Lemaire, L.; Sindji, L.; Franconi, F.; Le Jeune, J. J.; MonteroMenei, C. N., Brain research 2009, 1255, 18-31. DOI 10.1016/j.brainres.2008.12.013.

[29] Reddy, A. M.; Kwak, B. K.; Shim, H. J.; Ahn, C.; Cho, S. H.; Kim, B. J.; Jeong, S. Y.; Hwang, S. J.; Yuk, S. H., Contrast media \& molecular imaging 2009, 4 (3), 118-26. DOI 10.1002/cmmi.271.

[30] Chen, C. L.; Zhang, H.; Ye, Q.; Hsieh, W. Y.; Hitchens, T. K.; Shen, H. H.; Liu, L.; Wu, Y. J.; Foley, L. M.; Wang, S. J.; Ho, C., Molecular imaging and biology : MIB : the official publication of the Academy of Molecular Imaging 2011, 13 (5), 825-39. DOI 10.1007/s11307-010-0430-x.

[31] Landazuri, N.; Tong, S.; Suo, J.; Joseph, G.; Weiss, D.; Sutcliffe, D. J.; Giddens, D. P.; Bao, G.; Taylor, W. R., Small 2013, 9 (23), 4017-26. DOI 10.1002/smll.201300570.

[32] Wang, L.; Neoh, K. G.; Kang, E. T.; Shuter, B.; Wang, S. C., Biomaterials 2010, 31 (13), 3502-11. DOI 10.1016/j.biomaterials.2010.01.081.

[33] Xu, C.; Miranda-Nieves, D.; Ankrum, J. A.; Matthiesen, M. E.; Phillips, J. A.; Roes, I.; Wojtkiewicz, G. R.; Juneja, V.; Kultima, J. R.; Zhao, W.; Vemula, P. K.; Lin, C. P.; Nahrendorf, M.; Karp, J. M., Nano letters 2012, 12 (8), 4131-9. DOI 10.1021/nl301658q.

[34] Khanbeigi, R. A.; Kumar, A.; Sadouki, F.; Lorenz, C.; Forbes, B.; Dailey, L. A.; Collins, H., Journal of Controlled Release 2012, 162 (2), 259-266. DOI DOI 10.1016/j.jconrel.2012.07.019.

[35] Dominici, M.; Le Blanc, K.; Mueller, I.; Slaper-Cortenbach, I.; Marini, F.; Krause, D.; Deans, R.; Keating, A.; Prockop, D.; Horwitz, E., Cytotherapy 2006, 8 (4), 315-7. DOI 10.1080/14653240600855905.

[36] Chastellain, M.; Petri, A.; Hofmann, H., Journal of colloid and interface science 2004, 278 (2), 353-60. DOI 10.1016/j.jcis.2004.06.025.

[37] Massart, R.; Dubois, E.; Cabuil, V.; Hasmonay, E., J Magn Magn Mater 1995, 149 (1-2), 1-5. DOI Doi 10.1016/0304-8853(95)00316-9.

[38] Petri-Fink, A.; Chastellain, M.; Juillerat-Jeanneret, L.; Ferrari, A.; Hofmann, H., Biomaterials 2005, 26 (15), 2685-94. DOI 10.1016/j.biomaterials.2004.07.023.

[39] Schulze, K.; Koch, A.; Schopf, B.; Petri, A.; Steitz, B.; Chastellain, M.; Hofmann, M.; Hofmann, H.; von Rechenberg, B., J Magn Magn Mater 2005, 293 (1), 419-432. DOI DOI 10.1016/j.jmmm.2005.02.075.

[40] Ode, A.; Duda, G. N.; Glaeser, J. D.; Matziolis, G.; Frauenschuh, S.; Perka, C.; Wilson, C. J.; Kasper, G., Journal of biomedical materials research. Part A 2010, 95 (4), 1114-24. DOI 10.1002/jbm.a.32909.

[41] Geissler, S.; Textor, M.; Kuhnisch, J.; Konnig, D.; Klein, O.; Ode, A.; Pfitzner, T.; Adjaye, J.; Kasper, G.; Duda, G. N., PloS one 2012, 7 (12), e52700. DOI 10.1371/journal.pone.0052700.

[42] Davis, L. A.; Dienelt, A.; zur Nieden, N. I., Methods Mol Biol 2011, 690, 255-72. DOI 10.1007/978-1-60761-962-8_17.

[43] Geback, T.; Schulz, M. M.; Koumoutsakos, P.; Detmar, M., BioTechniques 2009, 46 (4), 26574. DOI 10.2144/000113083.

[44] Hinderliter, P. M.; Minard, K. R.; Orr, G.; Chrisler, W. B.; Thrall, B. D.; Pounds, J. G.; Teeguarden, J. G., Particle and fibre toxicology 2010, 7 (1), 36. DOI 10.1186/1743-8977-7-36. [45] Ode, A.; Kopf, J.; Kurtz, A.; Schmidt-Bleek, K.; Schrade, P.; Kolar, P.; Buttgereit, F.; Lehmann, K.; Hutmacher, D. W.; Duda, G. N.; Kasper, G., European cells \& materials 2011, 22, 2642.

[46] Schneider, C. A.; Rasband, W. S.; Eliceiri, K. W., Nature methods 2012, 9 (7), 671-5.

[47] Schneider, G.; Guttmann, P.; Heim, S.; Rehbein, S.; Mueller, F.; Nagashima, K.; Heymann, J. B.; Muller, W. G.; McNally, J. G., Nature methods 2010, 7 (12), 985-7. DOI 10.1038/nmeth.1533.

[48] Kremer, J. R.; Mastronarde, D. N.; McIntosh, J. R., Journal of structural biology 1996, 116 (1), 71-6. DOI 10.1006/jsbi.1996.0013.

[49] Lesniak, A.; Fenaroli, F.; Monopoli, M. P.; Aberg, C.; Dawson, K. A.; Salvati, A., ACS nano 2012, 6 (7), 5845-57. DOI 10.1021/nn300223w. 


\section{WILEY-VCH}

620 [50] Schrurs, F.; Lison, D., Nature nanotechnology 2012, 7 (9), 546-8. DOI

$621 \quad 10.1038 /$ nnano.2012.148.

622 [51] Monopoli, M. P.; Walczyk, D.; Campbell, A.; Elia, G.; Lynch, I.; Bombelli, F. B.; Dawson, K.

623 A., Journal of the American Chemical Society 2011, 133 (8), 2525-34. DOI 10.1021/ja107583h.

624 [52] Petri-Fink, A.; Steitz, B.; Finka, A.; Salaklang, J.; Hofmann, H., European journal of

625 pharmaceutics and biopharmaceutics : official journal of Arbeitsgemeinschaft fur Pharmazeutische

626 Verfahrenstechnik e.V 2008, 68 (1), 129-37. DOI 10.1016/j.ejpb.2007.02.024.

627 [53] Teeguarden, J. G.; Hinderliter, P. M.; Orr, G.; Thrall, B. D.; Pounds, J. G., Toxicological

628 sciences : an official journal of the Society of Toxicology 2007, 95 (2), 300-12. DOI

629 10.1093/toxsci/kfl165.

630 [54] Baker, M. I.; Walsh, S. P.; Schwartz, Z.; Boyan, B. D., Journal of biomedical materials 631 research. Part B, Applied biomaterials 2012, 100 (5), 1451-7. DOI 10.1002/jbm.b.32694.

632 [55] Petri-Fink, A.; Hofmann, H., IEEE transactions on nanobioscience 2007, 6 (4), 289-97.

633 [56] Chung, T. H.; Wu, S. H.; Yao, M.; Lu, C. W.; Lin, Y. S.; Hung, Y.; Mou, C. Y.; Chen, Y. C.;

634 Huang, D. M., Biomaterials 2007, 28 (19), 2959-66. DOI 10.1016/j.biomaterials.2007.03.006.

635 [57] Cengelli, F.; Maysinger, D.; Tschudi-Monnet, F.; Montet, X.; Corot, C.; Petri-Fink, A.;

636 Hofmann, H.; Juillerat-Jeanneret, L., The Journal of pharmacology and experimental therapeutics

637 2006, $318(1), 108-16$. DOI 10.1124/jpet.106.101915.

638 [58] Cartiera, M. S.; Johnson, K. M.; Rajendran, V.; Caplan, M. J.; Saltzman, W. M., Biomaterials 639 2009, 30 (14), 2790-8. DOI 10.1016/j.biomaterials.2009.01.057.

640 [59] Andreas, K.; Georgieva, R.; Ladwig, M.; Mueller, S.; Notter, M.; Sittinger, M.; Ringe, J., 641 Biomaterials 2012, 33 (18), 4515-25. DOI 10.1016/j.biomaterials.2012.02.064.

642 [60] Oyama, M.; Tatlock, A.; Fukuta, S.; Kavalkovich, K.; Nishimura, K.; Johnstone, B.; Robbins, 643 P. D.; Evans, C. H.; Niyibizi, C., Gene therapy 1999, 6 (3), 321-9. DOI 10.1038/sj.gt.3300839.

644 [61] Shirley, D.; Marsh, D.; Jordan, G.; McQuaid, S.; Li, G., Journal of orthopaedic research :

645 official publication of the Orthopaedic Research Society 2005, 23 (5), 1013-21. DOI

646 10.1016/j.orthres.2005.01.013.

647 [62] Granero-Molto, F.; Weis, J. A.; Miga, M. I.; Landis, B.; Myers, T. J.; O'Rear, L.; Longobardi, 648 L.; Jansen, E. D.; Mortlock, D. P.; Spagnoli, A., Stem Cells 2009, 27 (8), 1887-98. DOI 649 10.1002/stem.103. 


\section{WILEY-VCH}

651

652

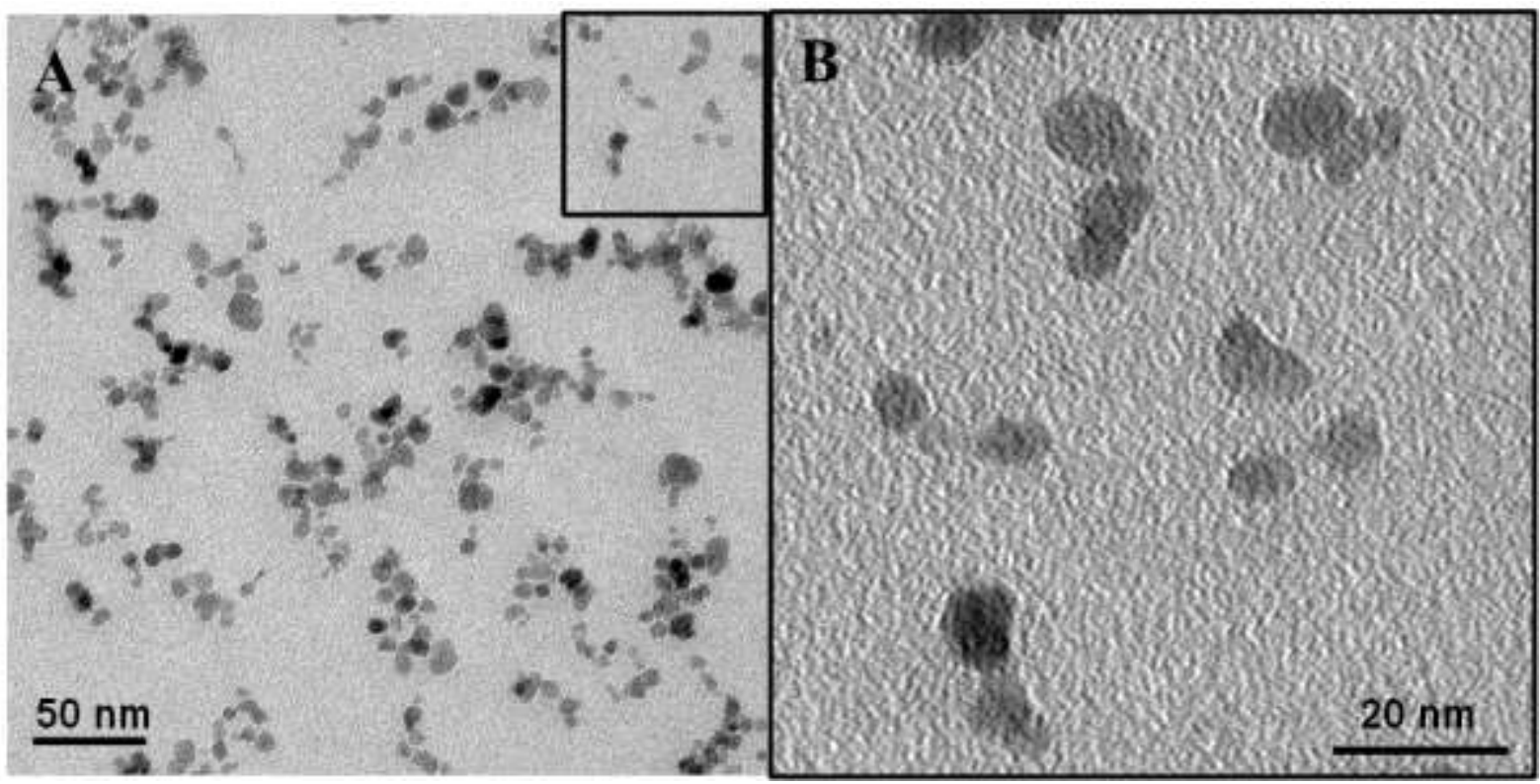

653 Figure 1. TEM pictures of A-PVA-SPIONs. (A+B) TEM micrographs show iron oxide

654 cores from A-PVA-SPIONs and were used to determine the mean average size of the $8 \mathrm{Fe}_{2} \mathrm{O}_{3}$

655 crystals

656 


\section{WILEY-VCH}

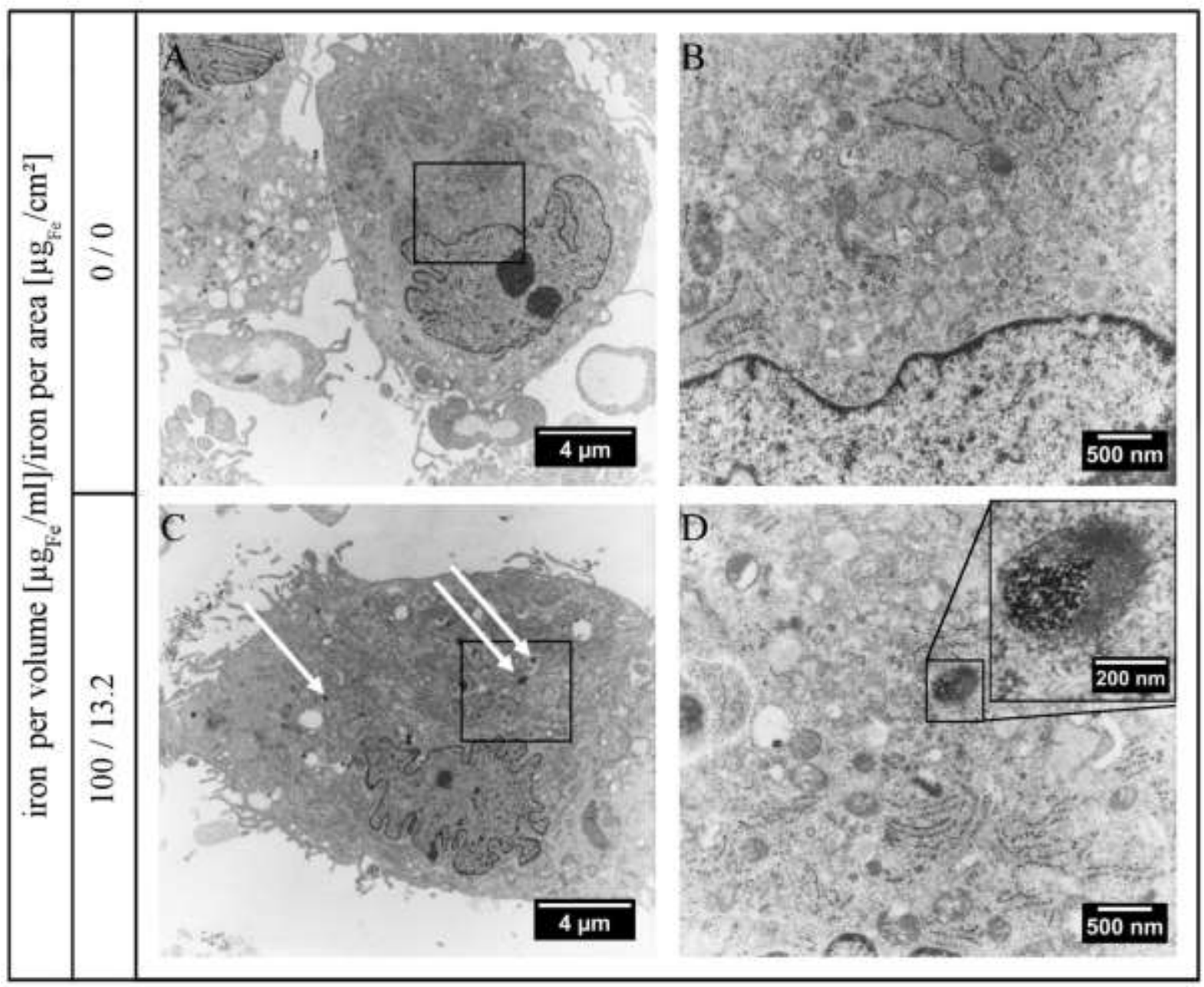

658 Figure 2. A-PVA-SPIONs are internalized by MSCs that store them in intracellular

659 vesicles. Shown are two representative pictures of (A, B) non-labeled and (C, D) A-PVA-

660 labeled MSCs at different magnification detection by TEM. A-PVA-SPIONs are visible as

661 intra-vesicular colloids (white arrows) in labeled MSCs that are absent in unlabeled control 662 cells. 


\section{WILEY-VCH}
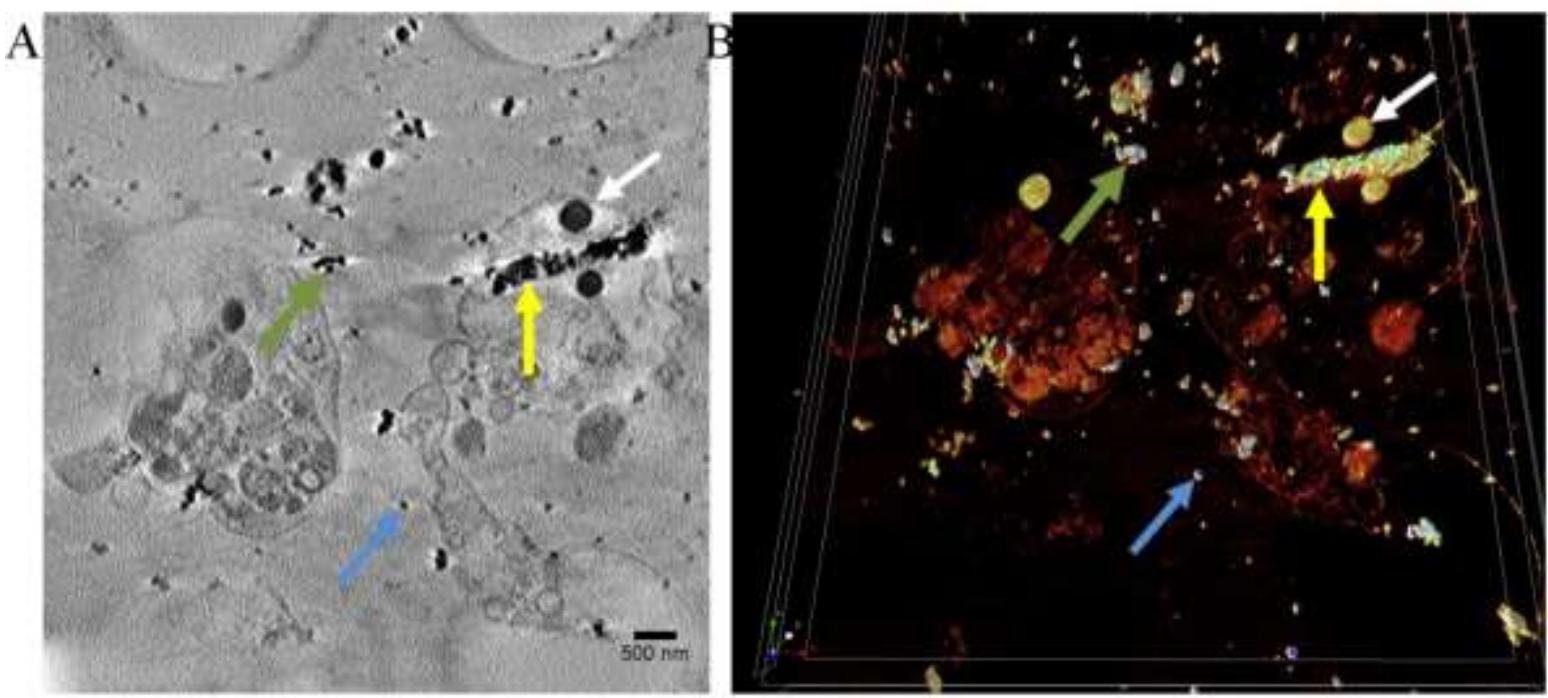

664

Figure 3. Internalized A-PVA-SPIONs are differently distributed in cytoplasm. The acquired tilt series of A-PVA-SPION-labeled MSCs by TXM allowed tomographic reconstruction. Shown are (A) one slice from z-stack and (B) subsequent 3D modeling. A-
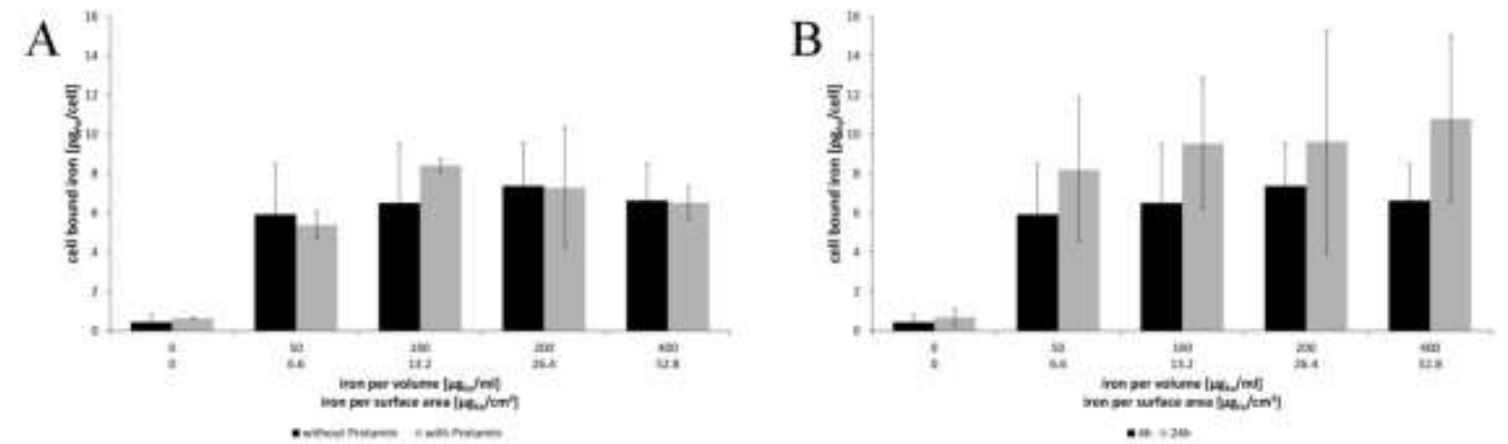

672 Figure 4. Efficient labeling of MSCs with A-PVA-SPIONs can be achieved at low

673 administered doses and does not require Protamine. MSCs were incubated with A-PVA-

674 SPIONs (A) for $4 \mathrm{~h}$ with and without Protamine under serum-free conditions and (B) for $24 \mathrm{~h}$

675 in the absence of Protamine. 


\section{WILEY-VCH}

676
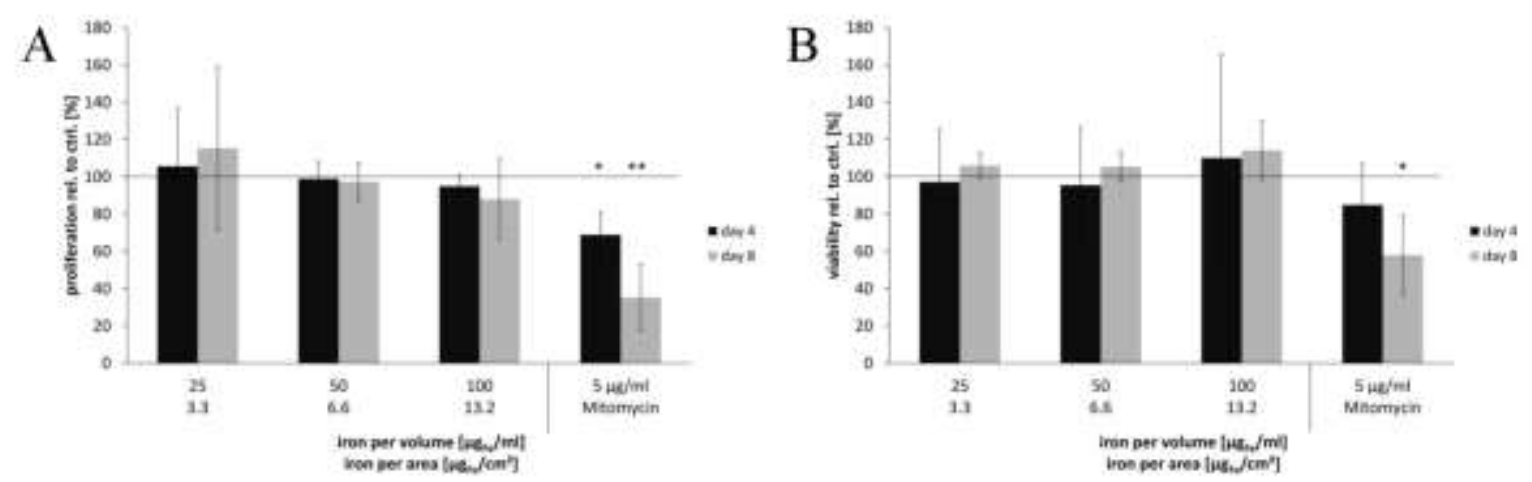

677 Figure 5. Proliferation and viability of MSCs are not affected by A-PVA-SPION-

678 labeling. (A) Proliferation and (B) viability of A-PVA-SPION-labeled MSCs was assessed 679 after four and eight days. 


\section{WILEY-VCH}
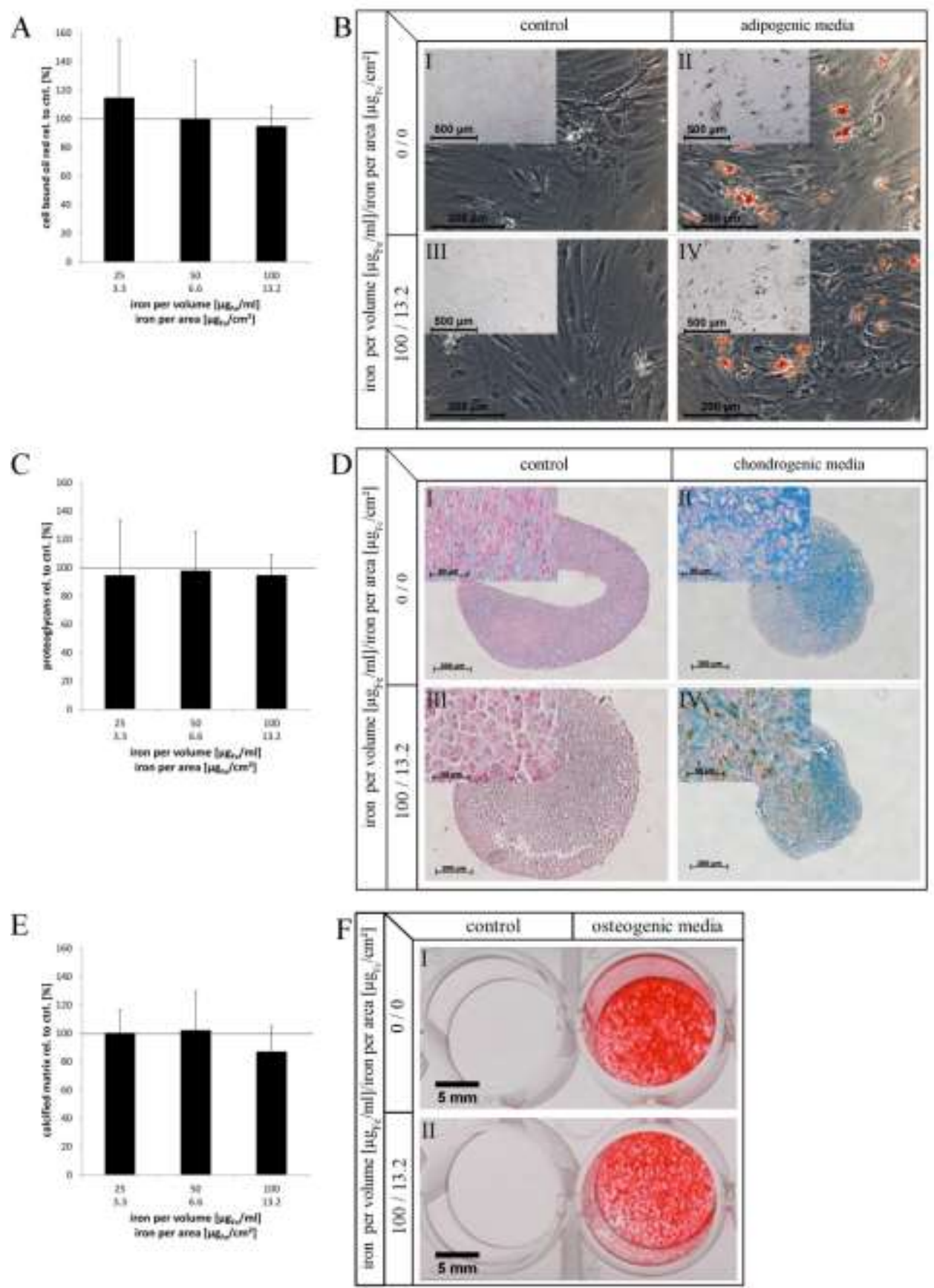

681 Figure 6. Differentiation capacity of MSCs is not influenced by A-PVA-SPIONs. A-PVA-

682 SPION-labeled MSCs were $(\mathrm{A}+\mathrm{C}+\mathrm{E})$ quantitatively and $(\mathrm{B}+\mathrm{D}+\mathrm{F})$ qualitatively investigated 683 towards $(\mathrm{A}+\mathrm{B})$ adipogenic differentiation by Oil red staining $(\mathrm{C}+\mathrm{D})$ chondrogenic 684 differentiation by proteoglycan assay and Alcian blue staining, and (E+F) osteogenic differentiation by Alizarin red staining. 


\section{WILEY-VCH}
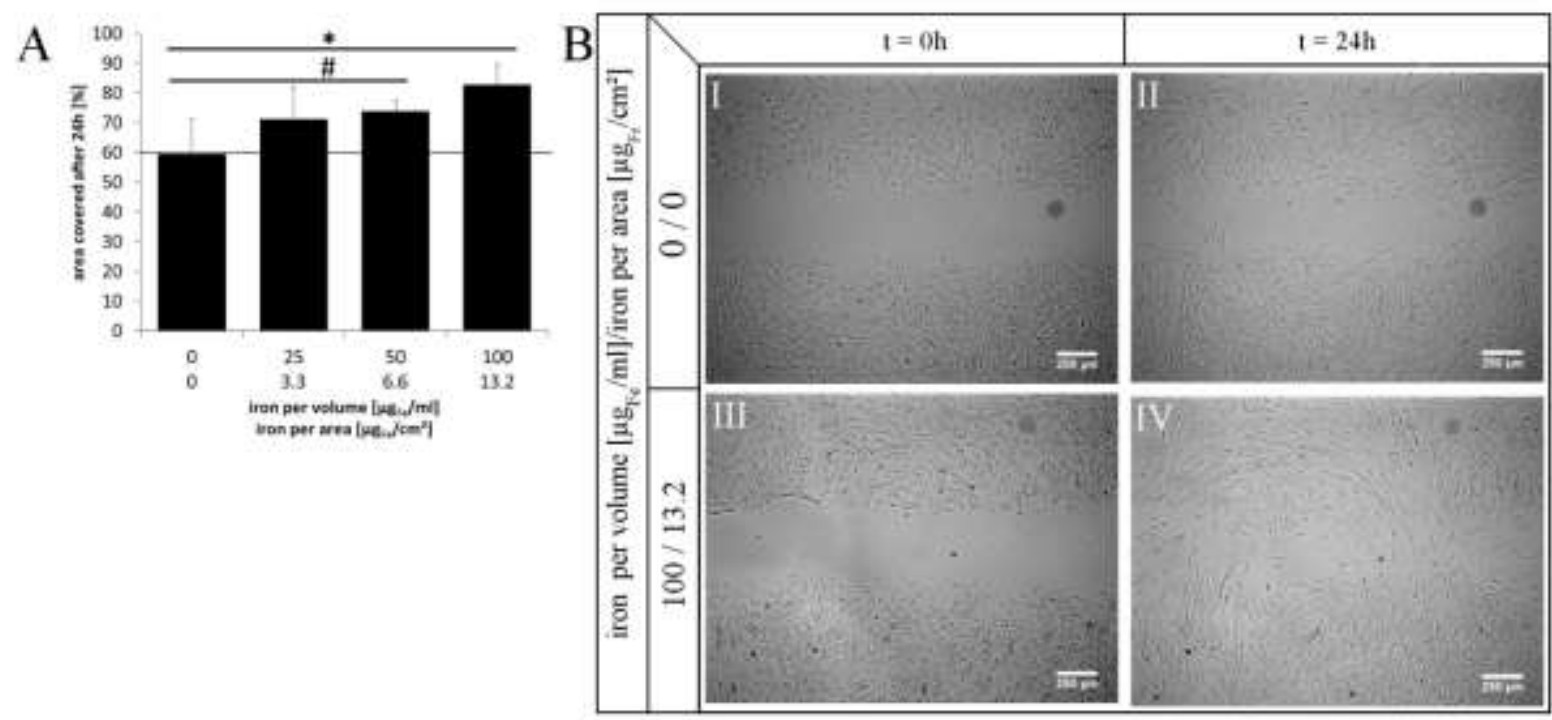

688

689 Figure 7. Migration of MSCs is stimulated by A-PVA-SPION-labeling. (A) Migration of

690 A-PVA-SPION-labeled MSCs was investigated in a wound healing assay for 24h (ANOVA,

691 Post Hoc Bonferoni; *, p = 0.001; \#, p = 0.069). (B) Representative images of the wound 692 healing gap from one donor are shown.

693

694 


\section{WILEY-VCH}

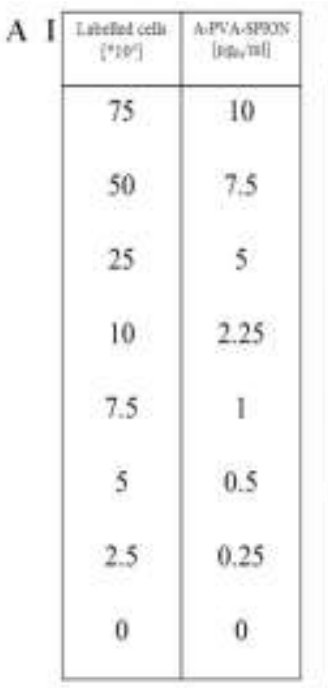

B

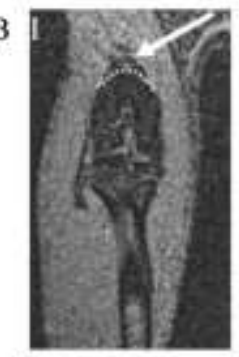

C



II
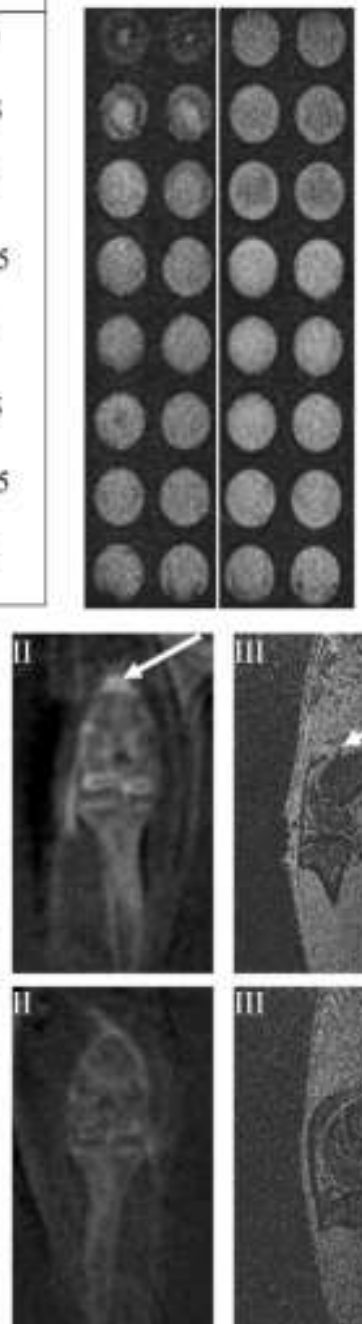

III
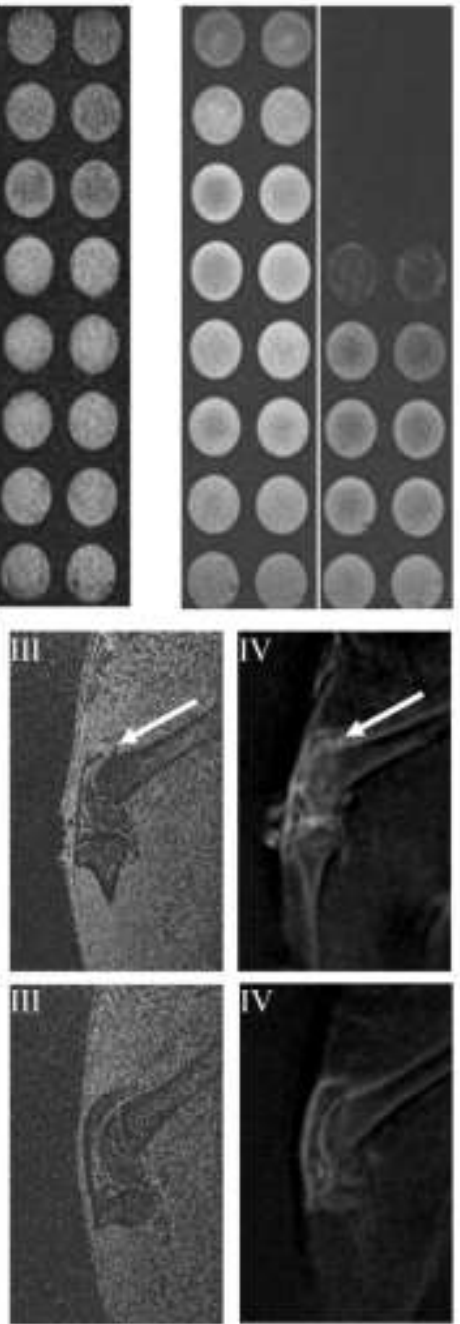

Figure 8. Visualization of A-PVA-labeled MSCs in MRI in vitro and in vivo. (A) A

697 diagrammatic representation showing the layout and the different concentrations of A-PVA-

SPION labeled MSCs and SPION alone used in the 24-well plate gel phantom study (I). T1

weighted gradient echo MR images of the gel phantom (II) and T2 weighted (STIR) MR

knee joint injected with A-PVA-SPION labeled MSCs and scanned in vivo. (C) Coronal (I, II) and sagittal (III, IV) views of rat knee joint injected with non labeled MSCs and scanned in vivo. Phantom was scanned using 1.5T MRI, rat knees were scanned in vivo using a 3T MRI.

704 White arrow: A-PVA-SPION labeled MSCs. Dotted white line: contour of the femoral 705 diaphysis. 


\section{WILEY-VCH}

707 Table 1. Physiochemical properties of A-PVA-SPIONs in different solvents

\begin{tabular}{ccccccc}
\hline Particles & Medium & $\begin{array}{c}\text { Concentration } \\
\left(\mathbf{m g}_{\mathrm{Fe}} / \mathbf{m L}\right)\end{array}$ & $\begin{array}{c}\mathrm{\gamma} \mathbf{F e}_{2} \mathbf{O}_{3} \\
\mathbf{c h r y s t a l} \\
(\mathbf{n m})\end{array}$ & $\begin{array}{c}\text { Hydrodynamic } \\
\text { diameter } \\
(\mathbf{n m})\end{array}$ & $\begin{array}{c}\text { Zeta } \\
\text { potential } \\
(\mathbf{m V})\end{array}$ & $\begin{array}{c}\mathbf{P V A} / \mathbf{F e} \\
\mathbf{r a t i o} \\
\left(\mathbf{m g}_{\mathbf{P V A}} / \mathbf{m g}_{\mathrm{Fe}}\right)\end{array}$ \\
\hline SPION & $\mathrm{HNO}_{3} 10 \mathrm{mM}$ & 10 & $7.2 \pm 2.5$ & $14 \pm 2$ & $+26 \pm 2$ & 0 \\
PVA-SPION & $\mathrm{HNO}_{3} 10 \mathrm{mM}$ & 5 & $7.2 \pm 2.5$ & $25 \pm 3$ & $+20 \pm 2$ & 9 \\
PVA-SPION & $\mathrm{DMEM}$ & 5 & $7.2 \pm 2.5$ & $42 \pm 2$ & $+21 \pm 5$ & 9 \\
& & 5 & $7.2 \pm 2.5$ & $45 \pm 2$ & $-25 \pm 5$ & 9 \\
\hline
\end{tabular}

708

709 Table 2. Dosimetry

\begin{tabular}{lllrrrr}
\hline administered dose & & & & & & \\
\hline iron per volume $\left[\mu \mathrm{g}_{\mathrm{Fe}} / \mathrm{ml}\right]$ & & 0 & 50 & 100 & 200 & 400 \\
iron per area $\left[\mu \mathrm{g}_{\mathrm{Fe}} / \mathrm{cm}^{2}\right]$ & & 0 & 6.6 & 13.2 & 26.4 & 52.8 \\
\hline delivered dose & & & & & & \\
\hline iron per area $\left[\mu \mathrm{g}_{\mathrm{Fe}} / \mathrm{cm}^{2}\right]$ & $4 \mathrm{~h}$ & 0 & 0.9 & 1.6 & 3.1 & 6.2 \\
& $24 \mathrm{~h}$ & 0 & 2.3 & 4.1 & 7.9 & 15.3 \\
iron per cell $\left[\mathrm{pg}_{\mathrm{Fe}} / \mathrm{cell}\right]$ & $4 \mathrm{~h}$ & 0 & 3 & 6 & 12 & 24 \\
& $24 \mathrm{~h}$ & 0 & 7.5 & 15 & 30 & 60 \\
\hline cellular dose & & & & & & \\
\hline iron per cell $[\mathrm{pg}$ & & & & & & \\
& $4 \mathrm{~h}$ & $0.4 \pm 0.3$ & $5.9 \pm 2.5$ & $6.5 \pm 3.0$ & $7.4 \pm 2.2$ & $6.6 \pm 1.9$ \\
& $24 \mathrm{~h}$ & $0.7 \pm 0.5$ & $8.2 \pm 3.6$ & $9.5 \pm 3.3$ & $9.6 \pm 5.7$ & $10.8 \pm 4.2$
\end{tabular}

710

711 


\section{WILEY-VCH}

712 Table of content

713

714 Amino-polyvinyl alcohol coated superparamagnetic iron oxide nanoparticles (A-PVA-

715 SPIONs) were used to label mesenchymal stromal cells (MSCs) for visualization in magnetic 716 resonance imaging. The A-PVA-SPIONs were non-toxic to MSCs and did not change their 717 differentiation potential. However, an increase in MSCs migration was observed. In 718 conclusion, labeling MSCs using A-PVA-SPIONs is feasible.

720 Keyword: mesenchymal stromal cells, superparamagnetic iron oxide nanoparticles,

721 polyvinylalcohol, magnetic resonance imaging, cell based therapies

723 Frank Schulze, Anke Dienelt, Sven Geissler, Paul Zaslansky, Janosch Schoon, Katja Henzler,

724 Peter Guttmann, Azza Gramoun, Lindsey A. Crowe, Lionel Maurizi, Jean-Paul Vallée,

725 Heinrich Hofmann, Georg N. Duda*, Andrea Ode

\section{Title}

Amino-polyvinyl alcohol coated superparamagnetic iron oxide nanoparticles are suitable for monitoring of human mesenchymal stromal cells in vivo

ToC figure ((Please choose one size: $55 \mathrm{~mm}$ broad $\times 50 \mathrm{~mm}$ high or $110 \mathrm{~mm}$ broad $\times 20 \mathrm{~mm}$

732 high. Please do not use any other dimensions))

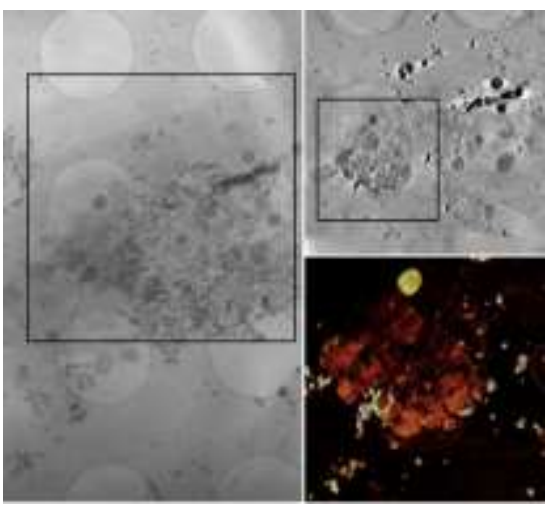

